\title{
Erratum to: Visual tracking in complex scenes through pixel-wise tri-modeling
}

\author{
Kwang Moo Yi · Hawook Jeong • Byeongju Lee • \\ Jin Young Choi
}

Published online: 29 July 2015

(C) Springer-Verlag Berlin Heidelberg 2015

Erratum to: Mach Vis Appl (2015) 26:205-217

DOI 10.1007/s00138-015-0658-1

In the original publication of the article, the co-author name was incorrectly spelled in the author group. The name should appear as "Byeongju Lee".

The online version of the original article can be found under doi:10.1007/s00138-015-0658-1.

K. M. Yi

Computer Vision Lab, Ècole Polytechnique Fèdèrale de Lausanne,

BC 309, Station 14, CH-1015 Lausanne, Switzerland

H. Jeong $\cdot$ B. Lee $\cdot$ J. Y. Choi $(\bowtie)$

Department of Electrical and Computer Engineering

(College of Engineering), ASRI, Seoul National Univ. \#048,

1 Gwanangno, Gwanak-gu, Seoul 151-744, Korea

e-mail: jychoi@snu.ac.kr 